\title{
ENSINO HÍBRIDO E A EDUCAÇÃO À DISTÂNCIA: AS DIFERENÇAS METODOLÓGICAS
}

\author{
Alana Gabriele da Silva ${ }^{1}$ \\ Helenice Barroso Araújo ${ }^{2}$ \\ Maria Veronica Oliveira Simão ${ }^{3}$
}

RESUMO: O coronavírus modificou a realidade das pessoas, principalmente, no âmbito educacional, no qual as escolas foram obrigadas a fecharem as portas para a contenção do vírus, e o processo de ensino e aprendizagem ocorreu por meios alternativos, como a internet. Como resultado, as Tecnologias de Informação e Comunicação (TICs) adentraram definitivamente na vida dos alunos e professores, logo, ocorreu uma grande mistura de metodologias, sobretudo entre a Educação à Distância e o Ensino Híbrido causando, então, uma confusão da utilização destas. Portanto, a partir de investigações em estudos prévios este artigo visa explicar as diferenças entre as metodologias e descrever que elas são muito distintas, apesar de parecerem semelhantes.

Palavras- chave: Ensino híbrido. Educação à distância. Metodologias.

ABSTRACT: Coronavirus has changed people's reality, especially in the educational sphere, in which schools were forced to close their doors to contain the virus, and the teaching and learning process took place through alternative means, such as the internet. As a result, Information and Communication Technologies (ICTs) definitively entered the lives of students and teachers, so there was a great mix of methodologies, especially between Distance Education and Hybrid Teaching, causing confusion in their use. Therefore, based on investigations in previous studies, this article aims to explain the differences between the methodologies and describe that they are very different, despite appearing to be similar.

Keywords: Hybrid teaching. Distance education. Methodologies.

\footnotetext{
${ }^{\text {I }}$ Mestranda em Ciências da Educação pela Flórida Christian University (FCU), pós-graduada em Docência do Ensino Superior pelo instituto de ensino FAVENI, Graduada em Letras/ Inglês e Pedagogia pela Universidade do Sagrado Coração, Bauru e Professora da Educação Básica na rede pública do estado de São Paulo. E-mail:alanagdasilva@gmail.com.

${ }^{2}$ Mestranda em Ciências da Educação pela Flórida Christian University (FCU), Especialista em Supervisão, Gestão e Planejamento, Graduada em Pedagogia e em Letras Português/Espanhol, Professora do Ensino Fundamental e Médio na rede pública de ensino de Tutóia - Maranhão.E-mail: heleniceo2@hotmail.com.

3 Mestranda em Ciências da Educação pela Flórida Christian University (FCU), Especialista em Educação Especial, Graduada em Pedagogia e em Letras/Espanhol, Professora da Educação Básica na rede pública municipal de ensino no estado do Maranhão. E-mail: mvosimaoozı@gmail.com.
} 


\section{INTRODUÇÃO}

A chegada do coronavírus modificou a vida de todos, principalmente, no âmbito educacional, seja pela maneira como as pessoas enxergam a educação ou pela maneira em que ela foi transformada com a constante utilização das Tecnologias de Informação e Comunicação. Porém, embora os professores e alunos utilizem essas ferramentas no cotidiano, existe uma enorme probabilidade de eles estarem fazendo esse manuseamento de maneira equivocada, dado que há uma distinção de metodologias que envolvem as TICs.

Para que seja possível compreender melhor essa confusão, é necessário observar o cenário educacional brasileiro, no qual está sendo utilizado a metodologia de Ensino Híbrido. Todavia, essa implementação híbrida ocorreu em algumas escolas de maneira equivocada, porque existem rodízios de alunos, os quais frequentam a instituição em dias alternados, enquanto outros ficam em casa com atividades impressas para serem resolvidas e entregues na próxima aula. Mas, quando é analisado a teoria das metodologias da Educação à Distância e o Ensino Híbrido é possível perceber que existe uma enorme diferença.

Além disso, muitos funcionários do âmbito educacional fazem uma confusão ainda maior quando usam denominações da metodologia de Ensino Híbrido com a Educação à Distância, a qual foi criada para sanar a falta de tempo existente da modernidade.

Portanto, este artigo teórico visa diferenciar as possíveis confusões existentes entre o Ensino à Distância e o Ensino Híbrido, por meio de outros estudos já divulgados sobre os temas. Bem como, enfatizar alguns benefícios da adesão dessas metodologias nas salas de aula.

Para isso, este artigo está dividido em dois tópicos, sendo o primeiro um breve histórico das metodologias, e o segundo, o Ensino Híbrido e a Educação à Distância. Por fim, as considerações finais e as respectivas referências.

\section{BREVE HISTÓRICO DAS METODOLOGIAS DE ENSINO}

A história da educação e suas metodologias transcendem os anos e evoluem de acordo com sua época, isso acontece, porque cada período histórico tem suas especificidades, e como 
a educação de certa maneira, segue as demandas da história ela ainda está e continuará em constante transformação.

Os primeiros anos da educação foram marcados pelo tradicionalismo, ou seja, durante vários séculos, o foco dos métodos tradicionais de educação era o ensino, a partir da percepção do professor como uma figura de poder sobre o aluno (NAGAI \& IZEKI, 20I3; ARIÈS, 2006), portanto os alunos eram como uma tábula rasa, sendo assim, seus pensamentos, experiências e sentimentos não eram levados em consideração.

Porém, com a chegada da primeira Guerra Mundial, o sistema de educação começou a ser repensado, porque era necessário fazer uma comunicação mais rápida entre soldados de países diferentes durante as batalhas. Portanto, começou o pioneirismo em relação as metodologias, visto que precisava ser resolvido rapidamente o problema comunicativo.

Como já descrito, a Guerra Mundial alterou o modelo educacional, mas outros grandes períodos históricos como a Revolução Industrial também alteraram o mercado, e essa mudança exigiu uma reformulação nos padrões educacionais, pois eram necessários pessoas mais rápidas para executar os serviços, sobretudo, de produção. Resultado, então, em um ensino rápido e de pouca reflexão.

A história, como já mencionado, tem uma constante em relação a criação e inovação de metodologias para sanar as adversidades impostas pela cultura de cada época e espaço geográfico.

Portanto, é possível destacar as ideias de aprendizagem pelo condicionamento de Montessori, a aprendizagem por experiência de Frente, bem como as teorias de aprendizagem de Vygotsky e Piaget, a crítica ao modelo de educação bancária de Paulo Freire, a aprendizagem significativa de David Ausubel e o construtivismo de Foucault (FARIAS, MARTIN \& CRISTO, 2015), ou seja, grandes pensadores e pesquisadores que revolucionaram a educação com suas metodologias.

Embora cada metodologia tenha suas características, após algumas décadas, os alunos finalmente foram reconhecidos como seres agentes de sua aprendizagem, devido a construção social diária, as quais contém experiências de grande valia. Consequentemente, "as metodologias ativas têm o potencial de despertar a curiosidade, à medida que os alunos 
se inserem na teorização e trazem elementos novos, ainda não considerados nas aulas ou na própria perspectiva do professor.” (BERBEL, 20II, p.28), então, as metodologias ativas ganharam espaço e dominaram o mundo educacional.

Com a evolução e a chegada da Modernidade, também houve uma transformação na área educacional, posto que o tempo cronológico aparentava ter encurtado, devido a facilidade oferecida pelos aparelhos eletrônicos, e os excessos de compromissos na agenda do homem. Por conseguinte, começa uma nova era educacional.

As Tecnologias de Informação e Comunicação (TICs), chegaram para revolucionar a educação. Elas são, como o próprio nome, ferramentas para comunicação e aquisição da informação em tempo real. E, fazem parte da vida de, praticamente, todos os habitantes. Como resultado, foram levados para a escola e inseridos de maneira estratégica dentro de metodologias, objetivando o protagonismo dos alunos.

\section{I.I As metodologias de ensino e as TICs}

As metodologias de ensino virtual que vêm transformando a educação brasileira são recursos tecnológicos que chegaram para alargarem o campo cognitivo de toda comunidade escolar. Embora recentes, mas as experiências com estas ferramentas deixam indícios de que elas chegaram para dinamizar o fazer pedagógico das escolas do Brasil, bem como realizar atividades jamais imaginadas na ausência delas.

Pocinho e Gaspar (2012, p. I45) defendem que "o sistema de ensino baseado neste modelo tenderá a estimular a criatividade e a dinâmica da aprendizagem na sala de aula, tendo resultados que se esperam cada vez melhores, tornando-os mais estimulantes e interativos”. Assim, com a grande representatividade das TICs na aprendizagem surge um novo paradigma escolar com ênfase na maneira de buscar os conhecimentos na era da informação virtual.

Neste sentido, são inúmeras as metodologias que envolvem a aprendizagem. Entre elas têm-se a Educação a Distância e o Ensino Híbrido. Mas, para compreender o funcionamento destas e de outras metodologias tecnológicas é preciso conhecer as definições 
das Tecnologias da Informação e Comunicação, instrumento estratégico que, atualmente, são muito significativos para o conhecimento cognitivo dos discentes.

Assim, Lobo (2015, p. 17) define a "Tecnologia da Informação e Comunicação - TIC como um conjunto de recursos tecnológicos que, quando integrados entre si, proporcionam a automação e/ou a comunicação no ensino e na pesquisa científica e etc". Pois, estes recursos são meios de união, distribuição e compartilhamento de informação.

A chegada das novas tecnologias foi determinante para criação de novos modelos pedagógicos. Para muitas pessoas a oportunidade ideal para conquistar um curso de graduação, mas as crenças frente à nova maneira de produzir conhecimentos limitavam o estudo, apenas, à sala de aula. Contudo, Oliveira (2020, p. 3) versa que à "distância - ou separação espacial - não implica, necessariamente, divergência temporal (cronológica)", resultando em um acesso com mais facilidade.

As incompreensões a cerca do uso das TICs causaram muitas críticas e preconceito em relação ao ensino a distância, pois segundo as crenças, quem estuda nessa modalidade não aprende porque o professor e o aluno não estão presentes no mesmo espaço de aprendizagem.

Para Vilaça (2010) apud Oliveira (2020, p. 3) "alunos e professores podem estar em locais diferentes participando sincronicamente de uma mesma atividade com fim pedagógico, como, por exemplo, em atividades mediadas por chat”, desmitificando a ideia de que o aluno que estuda a distância não aprende. Fato comprovado com as grandes demandas de cursos superiores ofertados via EaD por muitas instituições educacionais do país.

Aceitabilidade das TICs começou a crescer quando as escolas perceberam que as estratégias tecnológicas eram alternativas que podiam contribuir para um melhor engajamento dos alunos nas aulas, impulsionando a educação, em especial a educação virtual, tornando mais uma excelente ferramenta metodológica para o ensino aprendizado.

A introdução das tecnologias da informação e da comunicação no processo educacional tem a finalidade de intensificar a melhoria dos recursos midiáticos utilizados em sala de aula pelos professores que atuam em uma instituição de ensino, seja ela particular ou pública. A tecnologia vem modificando os conceitos de toda a sociedade ao longo de sua evolução pela história. (GERALDI; BIZELLI, 2015, p. I19). 
As tecnologias da informação e da comunicação quando inseridas no espaço escolar enriquecem e otimizam as aulas, estimulando a capacidade de construção do conhecimento. Segundo Badalotti (2017), a realidade virtual invade as salas, criando um ambiente mais atrativo para o aluno, fazendo com que ele vivencie o mundo em uma nova perspectiva.

A utilização das TICs e a inserção da internet nas salas de aula deixaram as escolas digitalmente preparadas para trabalhar o currículo por meio das diversas ferramentas metodológicas, tornado o processo de aprendizagem mais natural para os alunos. Bem como “desenvolver com TIC, os trabalhos administrativos e de gestão" (LAGARTO 2013, p. 6). Portanto, pode-se dizer que escola está vivenciando uma cultura digital, sendo comprovado com a difusão do Ensino à Distância e a implantação do Ensino Híbrido nas escolas.

\section{EDUCAÇÃO À DISTÂNCIA E O ENSINO HÍBRIDO}

A Educação à Distância surgiu um pouco antes dos aparelhos eletrônicos como telefones, e computadores com internet. Ela chegou com o intuito de levar a educação de maneira ampla, principalmente, as pessoas que tinham mais dificuldades de encontrar tempo para estar em espaços físicos de ensino.

Portanto, com a chegada da internet e a completa inserção das TICS, a modalidade EaD é efetivada através do intenso uso de tecnologias de informação e comunicação, podendo ou não apresentar momentos presenciais (MORAN, 2009), ou seja, embora ela ocorra pelo meio digital, ela também pode contemplar encontros presenciais.

Já o Ensino Híbrido, surge depois das TICs, e contempla o aprendizado, sendo uma parte obrigatoriamente online, então "Ensino híbrido é qualquer programa educacional formal no qual um estudante aprende, pelo menos em parte, por meio do ensino on-line, com algum elemento de controle dos estudantes sobre o tempo, o lugar, o caminho e/ou ritmo". (HORN, MICHEL B., STAKER, HEARTHER, 2015. p. 34), ou seja, o aluno se adequa ao seu processo de aprendizagem.

Embora exista diferença entre as duas metodologias, tanto na utilização quanto na prática ainda ocorre uma confusão quando a aplicação e utilização delas. Essa adversidade pode ter ocorrido pela rápida, e quase instantânea, inserção da tecnologia com a chegada da pandemia, que obrigou o isolamento social. 
A acelerada troca de cotidiano, consequentemente, não abriu espaço para que essas metodologias tenham sido estudadas e conhecidas pelos profissionais da educação, sobretudo, os mais antigos. Até mesmo os jovens encontram dificuldades na hora de utilização do Ensino Híbrido e a Educação à Distância. Todavia, essa utilização intensificada das TICS já ocorre e continuará.

O conceito tende, então, a se transformar, quanto à educação e a distância, pois uma das macrotendências que se pode vislumbrar do campo educacional, após a pandemia, é uma “convergência de paradigmas", a qual faz a unificação do ensino presencial e a distância em formas novas e diversificadas, utilizando muito mais as TICS.

Ademais, os professores também alterarão ainda mais os seus papéis, sendo não apenas mais um tutor, mas um curador. Para Moran (2012, p. 33) “o papel do professor - o papel principal - é ajudar o aluno a interpretar esses dados, a relacioná-los, a contextualizálos. O papel do educador é mobilizar o desejo de aprender, para que o aluno se sinta sempre com vontade de conhecer mais", tornando-o, então, em um cidadão crítico e ativo, que seja capaz de resolver seus problemas. Resultando, em alunos protagonistas.

\section{I EDUCAÇÃO À DISTÂNCIA}

A Educação à Distância é o formato metodológico de ensino que vem sendo difundido pelo Brasil há algumas décadas. Somente com a chegada da pandemia que esta modalidade ganhou ênfase, pois muitas pessoas não sabiam diferenciar dos modelos metodológicos que surgiram neste período. Para tanto, existem muitas definições a respeito dela.

Badalotti (2017, p. ır6) define Educação à Distância como "uma nova forma de ensino, na qual acontece em local diferente de ensino e deve ser estruturada e medida por tecnologias". Integrando a aprendizagem e aproximando aluno e professor de forma virtual.

Para Preti (2009) a EaD se apresenta como um conjunto de métodos, técnicas e recursos que são postos à disposição de população estudantil dotada de mentalidade e motivação suficiente para seguir um regime de disciplina durante o processo de 
aprendizagem para a aquisição do conhecimento em todos os níveis de ensino para a qualificação profissional.

Pode-se ainda considerar, em outras palavras, que a EaD seria um modelo de ensinar e aprender que possibilita ao estudante, que não possui condições de frequentar diariamente uma instituição de ensino, a oportunidade de adquirir os conteúdos que são propostos aos alunos da educação presencial. Desse modo, entende-se que a EaD se trata de uma modalidade que possibilita a superação de distâncias geotemporais ao possibilitar ao discente a oportunidade de organização do seu tempo e do seu espaço para estudar. (OLIVEIRA, 2020, p. 7).

Neste contexto, a EaD favorece de forma significativa, pois ela se tornou a estratégia tecnológica de ensino mais requisita nos últimos tempos pela facilidade de ofertar uma diversidade de cursos de qualificação para jovens e adultos. Além disso, as pessoas que estudam neste formato não precisam se deslocar das suas casas para estudar, podendo até mesmo acessar as aulas no local de trabalho.

Este formato de ensino também contribui muito para a diminuição de gastos das instituições educacionais que ofertam estes serviços, limitando o contrato de recursos humanos. Em contrapartida, exige uma qualificação mais específica de quem esta à frente desta metodologia, já que para lidar com estas ferramentas é preciso entender de tecnologia.

Diante deste cenário surgem as dificuldades na utilização desse método educacional, uma vez que, de acordo com Preti (2021) ainda existe uma grande resistência em buscar conhecimento no campo da Educação a Distância. Entende-se, portanto, que o pré-conceito das modalidades de ensino virtuais ainda não foram superados, em virtude das exigências que as novas tecnologias necessitam para se fazerem presentes nos ambientes sociais e pedagógicos.

Entretanto, os benefícios e as potencialidades da utilização da Educação à Distância trazem novas maneira de trabalhar a pedagogia. Conforme Oliveira (2020, p. 14) a modalidade Educação à Distância “vem aumentando sua colaboração na expansão da democratização do ensino e na aquisição dos mais variados saberes e conhecimentos, principalmente por se constituir numa ferramenta capaz de alcançar um grande número de sujeitos simultaneamente". Além do mais, é um formato de ensino bastante flexível.

Camacho (2020) ressalta a importância da flexibilidade e da acessibilidade aos cursos e disciplinas à distância, pois oferecem possibilidades de postagem de conteúdos, realização 
de trabalhos em grupo ou individual, avaliações e feedback de alunos, bem como o compartilhamento de trabalhos.

Com a interferência da pandemia, a Educação à Distância ascendeu, porém o método mais assertivo para ser utilizado é o Ensino Híbrido, que hoje traz novas possibilidades de aprendizagem e podem ser encontradas em ambientes virtuais, como as plataformas de aprendizagem que são de fácil acesso, tornando o ensino sem barreira em tempo de pandemia da Covid-rg.

\subsection{Ensino híbrido}

Dentro desse novo momento educacional, o Ensino Híbrido tornou-se uma das maiores tendências da educação brasileira, por ser uma metodologia que tem métodos que auxiliem na aprendizagem de forma online e offline. O Ensino Híbrido é responsável por absorver o que existe de mais apropriado em cada ambiente para potencializar a experiência educativa.

Para Bacich, Tanzi Neto, Trevisan, (2015, p. 4I) "Híbrido significa misturado, mesclado, blended. A educação sempre foi misturada, híbrida, sempre combinou vários espaços, tempos, atividades, metodologias e públicos. Esse processo, agora, com a mobilidade e a conectividade é muito mais perceptível e amplo”. Permite o uso de diversos métodos, dos mais simples aos mais inovadores.

No entanto, ainda se percebe muitas dificuldades em relação ao uso dessa metodologia, um apego a metodologias tradicionais e, de certa forma, uma resistência a inovação. Almeida (2020, p. 17) destaca que, "a escola insistiu na demora, na conservação dos métodos, na tradição do ensino imutável: carteiras enfileiradas, livros com as páginas abertas onde o professor determina, e planejamentos feitos longe das demandas dos estudantes". É imprescindível que haja uma compreensão das transformações existentes neste novo contexto educacional.

Vale ressaltar que o Ensino Híbrido muitas vezes é confundido com o Ensino Remoto, no entanto, torna-se necessário deixar claro que o Ensino Remoto não é Ensino Híbrido. Segundo Almeida (2020) dentro do ensino híbrido, há momentos de escola remota, 
de aprendizagem remota e de ensino remoto, ou seja, em todo esse meio ocorre aprendizagem e ensino dentro e fora da escola.

De acordo com Moran, Masetto e Behrens (2013, p. 31) a "escola pode transformar-se em um conjunto de espaços ricos em aprendizagem significativas, presenciais e digitais, que motivem os alunos a aprender ativamente, a pesquisar o tempo todo, a serem proativos, a saber tomar iniciativas e interagir", ou seja, propiciar aos estudantes oportunidades de desenvolver suas habilidades e competências.

Enfim, uma das principais vantagens do Ensino Híbrido é permitir que o estudante faça a escolha de "seu caminho" dentro da metodologia, ou seja, que o estudante tenha essa liberdade de aprendizado e se afaste cada vez mais do ensino rotineiro e tradicional.

\section{CONSIDERAÇÕES FINAIS}

Com toda evolução e transformação no meio educacional existe uma grande diferença entre os métodos usados no Ensino Híbrido e a Educação à Distância.

É sabido que as metodologias tiveram um avanço significativo, tanto pela necessidade de serem aperfeiçoadas quanto pela inserção das TICs. No Ensino Híbrido se faz uso de métodos mais inovadores, em que permitem serem usados em momentos online e offline. Já na Educação à Distância ocorre por meio das tecnologias e permite o estudante a oportunidade de organizar seu tempo e espaço para estudos.

De fato, existem muitas metodologias, das mais tradicionais a inovadoras, que permitem ao estudante uma aprendizagem significativa. Portanto, em decorrência da falta de conhecimento ou comodismo, muitos professores ainda fazem uso das mais variadas metodologias e nem ao menos sabem distingui-las, como resultado, confundem a Educação à Distância com Ensino Híbrido. Também o Ensino Híbrido com o Ensino Remoto.

Para títulos de considerações finais, as metodologias ganharam espaços, e apesar de haver uma mistura em relação as suas utilizações e denominações é necessário identificá-las adequadamente para que sejam utilizadas de maneira correta, pois por meio delas a educação brasileira continua se transformando. 


\section{REFERÊNCIAS}

ARIÈS, P. (2006) História Social da Criança e da Família. Rio de Janeiro: LTC.

BADALOTTI, Greisse Moser. Educação e tecnologia. - Indaial. Uniasselvi, 2017.

BACICH, L.; TANZI NETO, A. e TREVISANI, F. Ensino Híbrido: personalização e tecnologia na educação. Porto Alegre: Penso, 2015.

BERBEL, N. A. N. (20II) As metodologias ativas e a promoção da autonomia de estudantes.

Semina: Ciências Sociais e Humanas, 32(I), 25-40

CAMACHO, Alessandra Conceição Leite Funchal et al. A tutoria na educação à distância em tempos de COVID-ı: orientações relevantes. Research, Society and Development, v. 9, n. 5, 2020.

DA SILVA POCINHO, Ricardo Filipe; GASPAR, João Pedro Marceneiro. O uso das TIC e as alterações no espaço educativo. Exedra: Revista Científica, n. 6, p. I43-154, 2012.

GERALDI, Luciana Maura Aquaroni; BIZELLI, José Luís. Tecnologias da informação e comunicação na educação: conceitos e definições. Revista on line de Política e Gestão Educacional, n. I8, 2015.

HORN, Michel B.; STAKER, Hearther. Blended: usando a inovação disruptiva para aprimorar a educação. Porto Alegre: Penso. 2015.

LAGARTO, Jose Reis. Inovação, TIC e sala de aula. As novas tecnologias e os desafios para uma educação humanizadora, v. I, p. 133-158, 2013.

LOBO, Alex Sander Miranda; MAIA, Luiz Cláudio Gomes. O uso das TICs como ferramenta de ensino-aprendizagem no Ensino Superior. Caderno de Geografia, v. 25, n. 44, p. 16-26, 2015 .

MARIN, M. J. S., LIMA, E. F. G., MATSUYAMA, D. T., SILVA, L. K. D., GONZALES, C., DEUZIAN, S., \& ILIAS, M. (2010) Aspectos das fortalezas e fragilidades no uso das Metodologias Ativas de Aprendizagem. Revista Brasileira de Educação Médica, 34(I), 13-20

MORAN, J. M. A educação que desejamos: novos desafios e como chegar lá. 5. ed. Campinas: Papirus, 2012.

MORAN, J. M.; MASETTO, M. T.; BEHRENS, M. A. Novas tecnologias e mediação pedagógica. 2I. ed. rev. atual. Campinas: Papirus, 2013. 
MORAN, J. M. O que é Educação a Distância. Universidade de São Paulo. Disponível em: 〈http://www.eca.usp.br/prof/moran/dist.htm〉. Acesso em:

20 set. 2021.

NAGAI, W. A., \& IZEKI, C. A. (2013) Relato de experiência com metodologia ativa de aprendizagem em uma disciplina de programação básica com ingressantes dos cursos de Engenharia da Computação, Engenharia de Controle e Automação e Engenharia Elétrica. Revista RETEC, 4, I-Io.

OLIVEIRA, Francisco Ariclene; DOS SANTOS, Ana Maria Sampaio. Construção do Conhecimento na Modalidade de Educação a Distância: Descortinando as Potencialidades da EaD no Brasil. EaD em Foco, v. ıo, n. I, 2020.

PRETI, Oreste et al. Educação a distância: fundamentos e políticas. - Cuiabá: EdUFMT, 2009 . 